\title{
Nigerian Public School Workers' Perception and Attitude to Pre-Retirement Counselling
}

\author{
P. N. Asuquo and Agnes Ebi Maliki* \\ 1. Educational Foundations, Guidance and Counseling, Faculty of Education \\ University of Calabar, Calabar \\ 2. Educational Foundations Department, Niger Delta University, Wilberforce Island, PMB 071, \\ 560001, Bayelsa State, Nigeria \\ *E-mail: agnesmaliki@yahoo.com
}

KEYWORDS Perception; attitude; retirement; counselling

ABSTRACT This study was designed to find out how public school workers nearing retirement perceived retirement counselling and their attitude to its programme. It was assumed that their perception that would be reflected in their attitude would not differ across age, sex, qualification, occupational level and professional status. The result, which however, showed a significant relationship between perception and attitude, revealed that public school workers in Nigeria showed less optimistic perception of retirement counselling and less favourable attitude towards its programme. Also, significant differences were shown to exist along qualifications and status lines in terms of their perception of pre-retirement counselling. The implications for retirement counselling were discussed.

\section{INTRODUCTION}

Over the past few years, research effort has focused on different aspects of retirement. According to some of these studies, retirement generates anguishing questions about the future in that it potentially changes the individual and his situation with far-reaching consequences for the society (Streich and Schneider, 1972; Denga, 1982; Asuquo, 2002). Super's (1951) self-theory in outlining the various stages of vocational development provided a comprehensive paradigm of work-life from birth to death that has highlighted the crucial nature of the retirement stage. Denga (1996) noted that the certainty of retirement like that of death bothers workers especially after they have attained mid-career. Accordingly, some people argue that preretirement counselling is a basic necessity if nearretirement workers are to be equipped to plan effectively for the demands of the future (Hunter, 1968, Ossofsky, 1977; Ekpo, 1995; Adeloye, 1999). Planning for retirement is a process that involves the past, present and future; to review current and past understanding. As we are aware, this requires a remarkably complex intellectual knowledge to identify areas for exploration, purpose and outline for action. It must be acknowledged, however, that pre-retirement counselling as a strategy for mediating retirement's effect and planning for future depends to a large extent on its perception and the response it elicits from would be users. This perspective has greatly influenced the motivation to conduct this study.

\section{Background and Review of Related Literature}

As a complex social phenomenon, retirement signifies the detachment from customary activity in business, industry or active service as full time employee (Manion, 1976). It can also be conceptualized as a process that separates an individual from a job role (Atchley, 1977) or as the termination of a pattern of life and a transition that deals with the reassessment of life resulting from old age, poor health, social pressure or weariness etc (Omoresemi, 1987; Asuquo, 2002). Certain basic features of retirement can be identified. In the first place, it is a period of transition or change in a variety of ways; change in values, habits, daily routine, self concept, role, the use of time, lifestyle, living arrangement, financial adjustment and adjustment in terms of age. Secondly, it involves reassessment of life in that retirement entails careful reordering of personal identity and life pattern especially as it affects new tasks, physical, mental and financial capabilities, prospects, social engagements and home maintenance (feeding, furniture, fees and vehicles). Furthermore, it provides opportunity for personal satisfaction, proper utilization of intellect and 
skills as well as for learning, growth in leisure and recreational activities.

Three major forms of retirement are identified in the literature, namely, voluntary, compulsory and mandatory (Omoresemi, 1987; Akande, 1995; Johnson, 1999; Olusekan, 1999). As the name implies, voluntary or self-retirement occurs when the individual, decides to quit active service for personal reasons irrespective of age, experience, length of service or retirement policies. This type of retirement depends more on the employee than the employer. The second type, compulsory or forced retirement is a situation in which the individual is forced or compelled to retire against the individual's expectation and when he is illprepared for it. It is usually viewed negatively in that it is unplanned and reasons might include inefficiency, old age, ill health, indiscipline and need for reduction of the workforce (Johnson, 1999). The third type, mandatory retirement is the normal (or expected form) in the sense that the person involved has reached the statutory age of retirement as specified already in the condition of service of the establishment. (Akinade, 1993). For instance, in Nigeria the age is specified for other civil servants while judges and lecturers retire at 65years or when an individual has put in 35 years of service.

Whether voluntary, compulsory or mandatory, retirement is known to have a lot of social, physiological, psychological and financial effects on retirees (Asuquo, 2002). As a highly personalized process it can be anticipated as benign, threatening or challenging. In view of the dreaded negative consequences occasioned by this period of transition characterized by loss of assumptive world, near-retirement workers need to prepare before coming to grips with these realities. Moreso, many people who attempt to adjust to the exigency of retirement do so in various ways depending on how prepared they are psychologically, socially and financially. This perhaps explains why many, people argue that the starting point to prepare for retirement is retirement counselling. By so doing, the psychosocial harassments and effects of retirement would be reduced or eliminated.

Baker (1982) defined counselling as a number of procedures used in assisting an individual in solving problems, which arise in various aspects of a person's life or in assisting the individual to maximize his/her overall personal development so that he/she could be more useful to the society, in which he/she lives. Pre-retirement counselling is a form of counselling. It can be conceptualized as a systematic and organized assistance offered to near-retirement workers in order to maximize their potentials while at work or out of work. This assistance provide them the opportunity to develop holistic and adequate plan for their years of retirement that addresses the practical, psychological, intellectual, creative, recreational and emotional needs of their lives. There are many aspects that need to be addressed when planning for a major life change that involves a transition like retirement. The pre-retirement counsellor is in a position to assist the client respond to issues of personal concern like finance, physical changes, emotional instability, recreation and leisure matters. Studies by Simpson, Back and Mcknney (1966) and Hunter (1968) show that pre-retirement counselling reduces uncertainties about retirement. Hence according to Ossofsky (1977: 25) "retirement preparation can provide information, it can clarify options about lifestyles, housing, it can alert people of things that need be done... and it can motivate them to look ahead with some optimism". Some of the importance of pre-retirement counselling as identified by Achley (1976) includes reduction in:

a. post-retirement shock and health problems;

b. negative stereo-typic ideas associated with retirement

c. dissatisfaction with retirement and tendency to miss one's previous job routine.

He concluded that pre-retirement counselling is very important and very useful in preparing people for the identity, changes and uncertainties that usually accompany retirement. It would also help in getting to know and decide on the right job or business endeavours to engage in, if need be.

Perception according to Dewey (1967) is the process by which organism maintains contact with its environment". He asserts that a man's perception is coloured by the assumptions he brings to bear on any particular occasion as well as the meaning he attaches to things, symbols, people and events or ideas. Ekpo (1995) demonstrated in a study that an individual perception is determined by the persons experience, intention and social needs. Accordingly, a perceiver is not passive but actively selects information to provide a basis for reducing uncertainly. Denga (1996) adds that what one perceives is not what one sees physically. He asserts that two people 
could see a thing differently but then each sees a reality that is unique to him and that is the reality that moderates his behaviour. The implication of these findings is that near-retirement workers are likely to perceive retirement counselling differently due to their experience, social needs, aspiration as well as information obtained from the environment (peers, colleagues, friends, neighbours, children etc).

Attitude underlies behaviour in such a significant way that it is necessary to understand it if we are to understand behaviour. Penner (1986) conceptualized it as a consistent disposition to respond to an object in some way (favourable or unfavourable). He asserts that it is unobservable but precedes a person's action. Attitude thus embodies feeling and emotions and is a major factor in determining our reactions and behaviour. Glen (1989) has described it as response pattern or a tendency to think or act in a particular way under a given set of circumstances.

Psychologists have proposed theoretical models to explain the structure of attitude and how it affects behaviour. A common view of it which is most representative is that it has three components namely, cognitive, affective and behavioural. The three, however, are interconnected and interdependent. The cognitive component comprises consistency in ideas, knowledge, beliefs and thoughts about the attitude object by the attitude holder. The affective component refers to the feelings that accompany the idea or belief while the behaviour component consists of the individual's action tendencies towards the attitude object or readiness for some kind of action. Attitude is said to provide the frame and reference for conduct of a person's life, that is all he thinks, does or sees is consistent with this reference. Attitude conditions behaviour in that an unfavourable attitude would cause a reaction either of avoidance or aggression. A neutral attitude leads to indifference, and a favourable attitude to a seeking behaviour.

Taken together, therefore, both perception and attitude are relevant to the success or otherwise of any pre-retirement counselling programme or service in that they are the inherent pre-conditions for its acceptance, patronage, and utilization. Moreso, perception and attitude are so basic in daily interaction that counsellors working on retirement cannot reap much success in their endeavours without studying the perception and attitude of the would be users of the service they are providing. Hence according to Asuquo (1997: 67) "The effectiveness of any counselling service is attributed largely to the prevailing climate of opinion towards such a service ... and counselees attitudes which reflect this opinion are indices of their willingness or otherwise to accept, patronize or utilize counselling services".

\section{Purpose of Study}

The purpose of this study, therefore, is to investigate the perception and attitude of selected Nigerian public school workers to pre-retirement counselling. The influence of age, sex, level and professional status on perception and attitude was also investigated. Specifically, this study was designed to find answers to the following questions. What percentage of public school workers' perception of pre-retirement counselling is high? What percentage of the public school worker's attitude to pre-retirement counselling is positive? To what extent is their perception of pre-retirement counselling related to their attitude to it? How is their perception of pre-retirement counselling and its effect on their attitude distributed across sex, age, educational distributed across sex, level and professional status? The finding of such a study could provide a basis for retirement counselling with benefit to the workers and the society. Retirement problems could also be eliminated or minimized if near retirement workers receive effective counselling. Further, information generated could form a basis for evaluating various aspects of retirement planning for the overall benefit of workers in Nigeria. On a broad basis, the study could provide significant data to theory and practice of career development. By and large, the outcome of the study could be useful to workers, employers, government and particularly guidance workers who constitute the primary users of the information.

\section{METHODS}

Respondents: The subjects for this study were 360 public school workers selected basically from teaching (primary and post primary). The stratified random sampling was adopted to ensure that the selection was representatives of the diversity of the population in a typical Nigerian School system (especially in terms of age, sex, 
professional status occupational level and qualification). To qualify for selection a participant had to be working for at least ten years and must have been aware or exposed to retirement planning. As a matter of fact, they were among the participant in a state wide retirement planning workshop organized by on NGO in conjunction with Cross River State Government (2003). The age of the respondents ranged from 28 to 52 years. A large percentage of the participants were married with children $(88 \%)$. Altogether the sample consisted of 360 participants (222 males and 138 females) all working in government managed schools.

Procedure: A Retirement Counselling Perception and Attitude Questionnaire (RCPAQ) was developed by the researcher specifically for the study. The questionnaire contained 42 items with three subscales. The first section requested subjects to supply information on such background or personal factors as age, sex occupational status and qualification. The other two subscales had 17 items each measuring perception of retirement counselling and attitude to retirement counselling respectively. The items in the questionnaire were rated on a 4-point Likert type scale that ranged from strongly agree to strongly disagree. Scores on agree and strongly agree were merged to give a single positive score while the reverse was done for disagree and strongly disagree. Based on this, the sum of the score for each subject for individual scales were determined and used for further analysis requiring independent t-test and product moment correlations coefficient as well as simple percentage. With a test-retest reliability coefficient of .82 and a construct validity index of .79 the instrument was deemed good enough for the study.

\section{RESULTS}

The results of the data analysis based on the objectives of the study are contained in tables 1 , 2 and 3 .

This result as presented below indicates that the correlation analysis between public school workers perception of and attitude to preretirement counselling produced correlation

Table 1: Correlations between perception of and attitude to pre-retirement counselling (No. 360)

\begin{tabular}{lc}
\hline Counselling Needs & $\begin{array}{c}\text { Perception/Attitude } \\
\text { Correlation Coefficient }\end{array}$ \\
\hline 1. Financial Concerns & .31 \\
2. Lifestyle Concerns & .38 \\
3. Personal Resource Concerns & .33 \\
\hline
\end{tabular}

Table 2: Responses in percentage obtained from 360 public school workers with regards to their perception and attitude to pre-retirement counselling

\begin{tabular}{|c|c|c|c|c|}
\hline \multirow[t]{2}{*}{ Counselling Needs } & \multicolumn{2}{|c|}{ Perception (\%) } & \multicolumn{2}{|c|}{ Attitudes (\%) } \\
\hline & Low & High & Negative & Positive \\
\hline Financial Concerns & 83 & 17 & 80 & 20 \\
\hline - Pension plans & 81 & 19 & 79 & 21 \\
\hline - Retirement savings plans & 70 & 30 & 80 & 20 \\
\hline - Annuities and Riffs & 40 & 60 & 78 & 22 \\
\hline - Retirement/Government benefits & 76 & 25 & 72 & 28 \\
\hline - Budgets & 64 & 36 & 56 & 44 \\
\hline - Housing & 30 & 70 & 83 & 17 \\
\hline - Wills & 63.3 & 36.7 & 75.4 & 24.6 \\
\hline Lifestyle Concerns & 64 & 36 & 72 & 28 \\
\hline - Health and Wellness & 58 & 42 & 75 & 25 \\
\hline - Nutrition & 62 & 38 & 70 & 30 \\
\hline - Time application (leisure, hobbies) & 67 & 33 & 62 & 38 \\
\hline - Boredom, Loneliness & 66 & 34 & 65 & 35 \\
\hline - Personal relationships & 70 & 30 & 64 & 36 \\
\hline - Relocation & 58 & 42 & 63 & 37 \\
\hline - Retirement shock & 63.6 & 36.4 & 67.3 & 32.7 \\
\hline Personal Resource Concerns & 55 & 45 & 60 & 40 \\
\hline - Personal worth & 60 & 40 & 55 & 45 \\
\hline - Self image / esteem & 70 & 30 & 65 & 35 \\
\hline - Skills/working in retirement & 58 & 42 & 71 & 29 \\
\hline - Net work of Social support & 60 & 40 & 55 & 45 \\
\hline - Adjustment/adaptation & 60.6 & 39.4 & 61.2 & 38.8 \\
\hline
\end{tabular}


Table 3: t-test for the differences between groups (sex, age, occupational level, qualification and professional status) in terms of their perception $(n=360)$

\begin{tabular}{lcccccc}
\hline Groups & $N$ & $X$ & $S D$ & $t$ & Crit. $t$. & $d f$ \\
\hline Male & 222 & 36.09 & 1.15 & & & \\
Female & 138 & 36.01 & 0.70 & 0.51 & 1.96 & 358 \\
Senior - staff (level 6 and below) & 240 & 25.30 & 1.70 & & & \\
Junior - staff (level 7 and above) & 120 & 24.00 & 1.90 & 1.70 & 1.96 & 358 \\
Higher qualification (above NCE) & 250 & 30.64 & 2.00 & & & \\
Lower qualification (below NCE) & 110 & 28.04 & 1.90 & $3.00^{*}$ & 1.96 & 358 \\
Older (above 40) & 150 & 40.10 & 1.77 & & & 358 \\
Younger (below 40) & 210 & 39.00 & 1.58 & 1.90 & 1.96 & 358 \\
Prof. trained (with teaching qualification) & 260 & 38.42 & 2.80 & & & \\
Non Prof. trained (without teaching qua.) & 100 & 35.10 & 2.00 & $2.18^{*}$ & 1.96 & 358 \\
\hline
\end{tabular}

*Significant at 0.05 , df $358,1.96$.

coefficients of $.31,38$ and .33 on all the classificatory variables of financial concerns, lifestyle concerns and personal resources concerns with regards to perception and attitude respecti-vely (see Table 1). These values are statistically significant at a .05 probability level in that the calculated value is greater than the critical. This suggests that there is a significant positive relationship between public school workers perception of and attitude to pre-retirement counselling. Thus, the higher the perception, the more favourable the attitude.

The result as presented below is a summary of participants' responses to item measuring perception and attitude of pre-retirement counselling among public school workers. It shows that a higher proportion of respondents $(60.6 \%)$ tended to be less optimistic in their perception of pre-retirement counselling. The result also show that a greater percentage of the subjects $(61.2 \%)$ tended to be less favourably disposed to pre-retirement counselling. Taken together, therefore, it shows that perception and attitude of public school workers are relatively low and unfavourable respectively(see Table2).

The next presentation below shows that the summary of t-test analysis produced a calculated $\mathrm{t}$-value of 3.00 and 2.18 for professional status and qualification respectively with regards to perception of pre-retirement counselling. This result indicates that the calculated $t$ was greater than the critical while the calculated $t$ for other groups (sex, age, occupational status) was less than the critical $t$ at 0.5 probability level. The result implies that significant differences exist along professional and qualification lines. There are, however, no differences in other groups in terms of their perception of pre-retirement counselling.

\section{DISCUSSION}

The major objective of this study was to find out how public school workers nearing retirement perceive retirement counselling and their attitude to it. According to the data presented in Table 1, the finding of the study shows that there is a significant positive relationship between perception and attitude of Nigerian Public School workers to pre-retirement counselling. This finding agrees with Form (1953), Glaxer, (1960), Uba (1986), Ekpo, (1995) and Asuquo (2002). These scholars in their individual studies discovered that there is a relationship between workers perception and their attitude to preretirement counselling. The practical implication of this finding is that the level of their perception reflects the status of their attitude. In other words, if near retirement public schools workers perception is high their attitude will be positive. The opposite also holds true.

The response patterns analysis of public school worker's perception and attitude to preretirement counselling rated, in percentages are presented in Table 2. These percentage ratings show that $60.6 \%$ of the respondents have low perception of pre-retirement counselling while $39.4 \%$ have high perception. Data presented on Table 2 also show that $61.2 \%$ of respondents have unfavourable attitudes towards preretirement counselling while $38.8 \%$ have favourable attitude. These results, thus, indicate that the knowledge/awareness of public school workers of pre-retirement counselling is quite low. The results tend to collaborate research findings of Greene (1969) as well as Asuquo (2002) who reported that their respondents showed lack of awareness/understanding of the importance of 
counselling. The study further indicate that a good number of the group of public school workers in this study are not favourably disposed to pre-retirement counselling. This is not encouraging because the more negative attitude they have about pre-retirement counselling, the more indifferent and avoiding their actions towards it would be (Ossfsky, 1977; Asuquo, 2002).

The results of this study further indicate that qualification and professional status significantly influenced public school workers perception of pre-retirement counselling. The results on professional status tend to collaborate the findings of Alao (1992) and Akinade (1993) while that on qualifications tend to agree with the findings by Harpaz and Kremer (1981). This perhaps, may be explained in terms of the differences in exposure and professionalization, which tended to make for the differentials in their perception.

\section{CONCLUSION}

This study has shown that Nigerian public school workers tends to show less optimistic perception of pre-retirement counselling and a less favourable attitude towards its programme. They seem quite unaware of the relevance as well as the importance of pre-retirement counselling and as such are less disposed to it. Furthermore, a significant positive relationship between public school workers perception of and attitude to pre-retirement counselling has been demonstrated. Also, significant differences have been shown to exist along qualifications and status lines in terms of their perception of pre-retirement counselling. Further studies should focus on determinants of public school workers perception and attitude to pre-retirement counselling.

This study has several implications for retirement counselling. First, counsellors with their allies in the helping profession should assist individuals to be aware of the impact and importance of pre-retirement counselling on the process of adjusting to retirement.

Secondly, based on these results efforts should be made by government, scholars and researchers to improve and sustain optimistic perception of pre-retirement so as to ensure more favourable attitude to it. Public enlightenment campaigns, workshops, seminars, symposia and talk shows are various avenues through which this can be done.
Retirement counselling is becoming an expanding area of counselling service. The world of work in Nigeria today is in a crisis state. It has witnessed mandatory retirement, mass retrenchment and unemployment beside voluntary retirement. The ailing economy and economic difficulties have had devastating effects on affected retirees and these all have generated a lot of concern among well meaning Nigerians and workers in particular. Counsellors have a tremendous challenge to research more into various aspects of retirement adjustment and devise means of helping retirees or even nearretirement workers cope with the exigencies of retirement.

\section{REFERENCES}

Adeloye, J. T. 1999. "Retirement: its Psychology, Management and Counseling Techniques." The Counselor, 17(1): $8-10$.

Akinade, E. A. 1993. Towards Satisfactory Retirement Socio-Psychological Approach. Lagos: Kola Okanlawon Services Ltd.

Akao, A. A. 1992. "Pre-retirement Counselling." Nigerian Journal Applied Psychology, 5: 20-28.

Alutu, A. N. G. 2005 "Psychological and Economic Problems Associated with Retirement. Implications for Counselling." The Counsellor, 17(1): 66-72.

Asuquo, P. N. 1997. "Students' Perception of School Counselling and their Attitudes towards its Programmes." Nigerian Journal of Educational Foundations, 1(1): 67-77.

Asuquo, P. N. 2002. "Factors in the Retirement decisions of Nigerian Public School Workers UBE Forum." Journal of Basic Education in Nigeria, 2(2): 69-78.

Archley, R. C. 1976. The Sociology of Retirement. Cambridge: Mass Schenkam Publishing Company.

Archley, R. C. 1977. The Social Forces in Later Life: An Introduction to Social Gerontology. California: Wadsworth Publishing Coy Inc.

Bakare, G. C. M. 1984. "The place of Guidance and Counselling in the Implementation of the National Policy on Education." The Journal of ANCOPS, 1 (5): 71-78

Denga, D. I. 1982. Managerial Psychology in Business and Educational Administration. Calabar: Rapid Educational Publishers Ltd.

Denga, D. I. 1996. Human Engineering and High Productivity in Industrial and Other Work Organizations. Calabar: Rapid Educational Publishers.

Dewey, J. 1967. Human Nature and Conduct: An Introduction to Social Psychology. New York: Modern Library.

Ekpo, C. I. 1995. Nigerian Workers Perception of Preretirement Counselling: The Case of Calabar Municipality in Cross River State. Unpublished Thesis. University of Calabar, Calabar, Nigeria.

Form, A. J. 1953. "Measurement of Students Attitude towards Counselling Services." Personnel and Guidance Journal, 37(27): 84-87.

Glazer, S. U. 1960. Counsellee Attitude towards 
Counselling Vocational Guidance Quarterly, 8(4): 235-238.

Greene, M. R. 1969. "Pre-retirement Counselling, Retirement Adjustment and the Older Employee." Journal on the Urban and Social Change Review, 27(20): 22-26

Harpers, 1. and Y. Kremmer. 1981. "Determinants of Continued and Discontinued Participation in Preretirement Training. An Israeli Case Study." Journal of Occupational Psychology, 5: 213-220.

Hunter, W. W. 1968. A Longitudinal Study of Preretirement Education. Michigan: University of Michigan Division of Gerantology.

Muellar, J. R. 1974. Principles of Classroom Learning and Perception. London: George Allen and Unwin Ltd.
Olusakin, A. M. 1999. Post Retirement Lifestyle of Some Nigerians and the Counselling Implications. The Counselor, 17(1): 8 - 10 .

Omoresemi, A. I. 1987. Retirement: A Real Transition. Kano: Abbos Educational Services Publications.

Ossofsky, J. 1977. "Retirement Preparation: A needed Addition to the Pension Plan." Journal on the Urban and Social Change Review, 10(2): 22-26.

Penner, L. A. 1986. Social Psychology Concepts and Applications. New York: West Publishing Company.

Super, D. E. 1951. "Vocational Adjustment Implementating a Self-Concept Occupations." American Psychologist, 30(12): 88-92.

Streib, G. E. and C. J. Schneider. 1972. Retirement in American Society. New York: Cornell University Press. 